\title{
وصف النكرة بالمعرفة وعكسه
}

\author{
باسو بلاواغاوو \\ baso.pallawagau@uin-alauddin.ac.id \\ جامعة علاء الدين الإسامياة الحكومية
}

\begin{abstract}
Abstrak
Perbedaan antara sifat dan mausuf dari segi makrifah dan nakirah memicu polimik di antara para pakar nahwu, sebagian dari mereka ada yang membolehkan dan sebagaian yang lain menolak. Dengan demikian rumusah masalah yang dijadikan tolak ukur dalam makalah ilmiah ini antara lain: Bagaimana pandangan pakar nahwu tentang perbedaan sifat dan mausuf dari segi makrifah dan nakirah? Apa dalil mereka?. Penelitian ini merupakan bagian dari penelitian deskriptif kualitatif dengan mempergunakan metode analitikal nahwu, dan teknik pengumpulan datanya melalui beberapa literatur pustaka. Hasil penelitian menunjukkan bahwa pandangan ahli nahwu tentang perbedaan sifat dan mausuf dari segi makrifah dan nakirah berbeda, Sibawaihi beserta pengikutnya tidak menerima perbedaan tersebut, sedangkan al-Khalil, al-Akhfash dan beberapa tokoh Kufa membolehkannya, sementara Ibnu Tharawah hanya membolehkan perbedaan itu jika mausufnya makrifah dan sifatnya nakirah, sebaliknya tidak boleh. Dalil yang mereka pergunakan kembali kepada nash dan qiyas.

Kata kunci: al-sifah, al-mausuf, al-makrifah, al-nakirah.
\end{abstract}

ملخصص

التخالف بين الصفة والموصوف في التعريف والتنكير أمر

أثار الجدل بين النحويين فقد أجازه بعضهم ومنعه بعض وفئه الآخر.

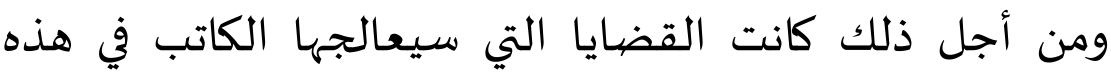

المقالة العلمياة وهي كما يلي: ما موقف النحويين في وصف النف النكرة

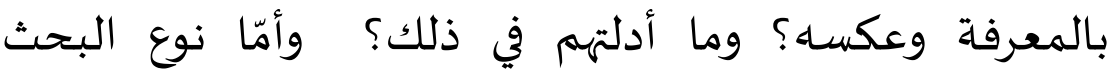

المستخدم في هذا المجال فهو البحث الوصيفي النوعي، باستخدام

المنهج التحليلي، وطريقة جمع البيانات تكون من الطريقة

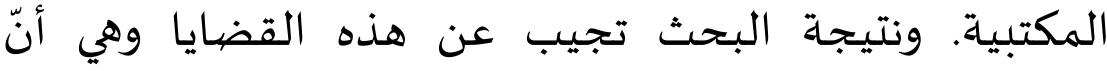

النحويين مختلفون في وصف النكرة بالمعرفة وعكسـا ذهب ذهب 


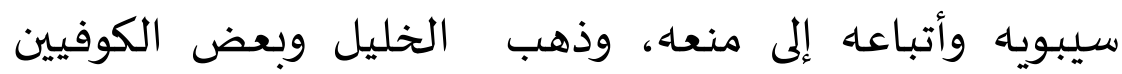

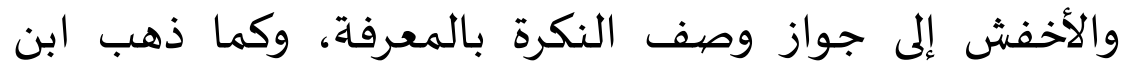

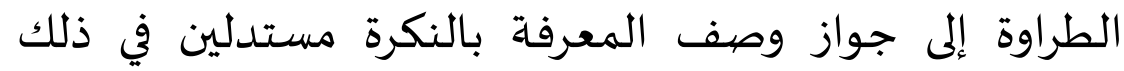
بالسماع والقياس. الكلمة السرية: الصفية، المعرفة، النكرة

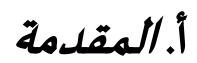

النعت اصطلاح الكوفيين، وربما قاله البصريون والأكثر عندهم الوصف والصفة، فالنعت والصفة واحد لا فرق بينهما. والنعت هو التابع الذي يكمل متبوعاه بدلالتهاه على معنى فيهاه أو فيما يتعلق بهاه. وينقسم النعت باعتبار معناه إلى نوعين: حقيقي وسبي النيبي.

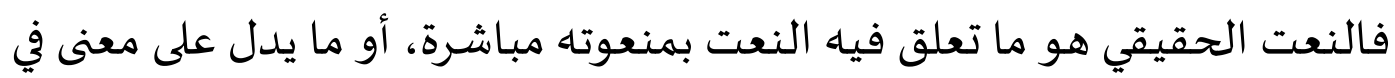

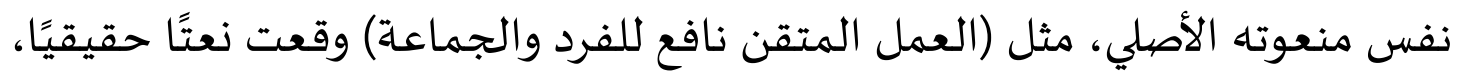

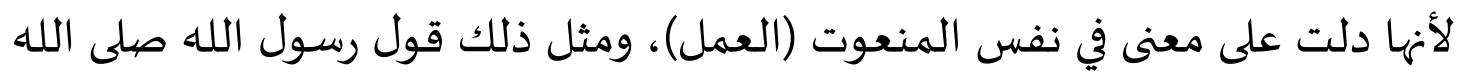

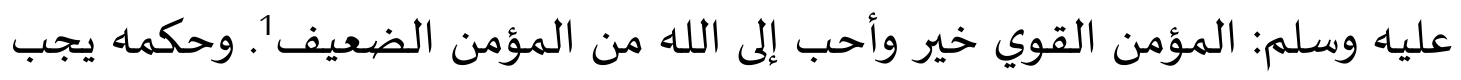

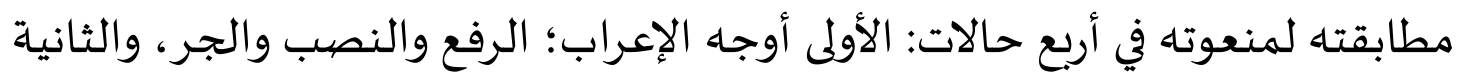

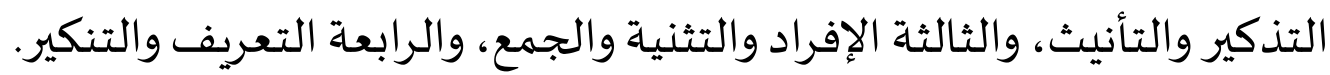

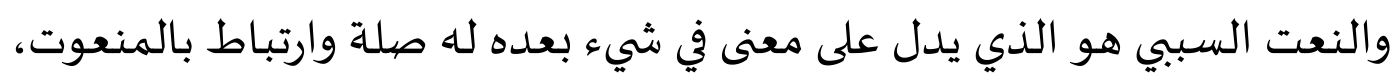

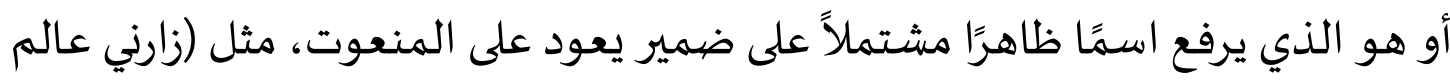

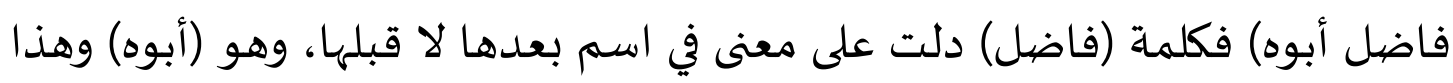

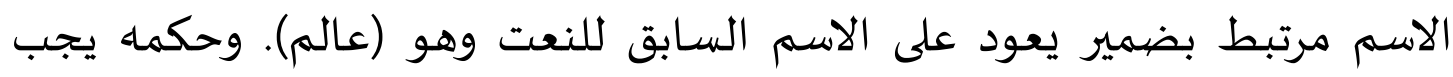

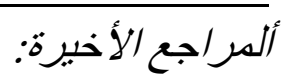
1 أبو الحسين مسلم بن الحجاج. صحيح مسلم، الجزء الثامن (المملكة العربية السعودية: بيت الأفكار الدولية، سنة 1998)، ص 56. 
مطابقتا لمنعوتاه في حالتين: الأولى أوجاء الإعراب؛ الرفع والنصب والجر، والثانية التعريف والتنكير².

\section{ب. موقف النحويين في وصف النكرة بالمعرفة وعكسه}

ذهب الخليل3، وبعض الكوفيين، والأخفش إلى جواز التخالف بين الصفة ولئ

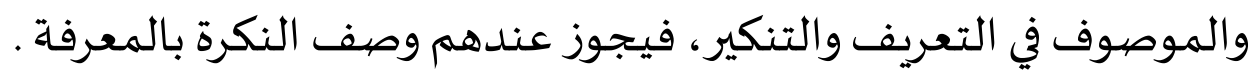

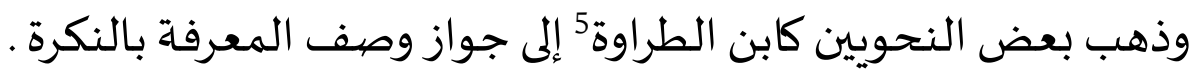

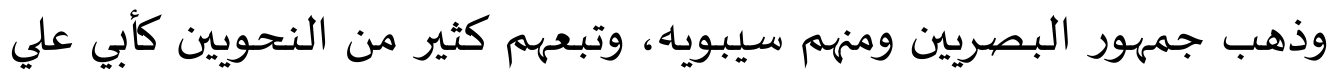

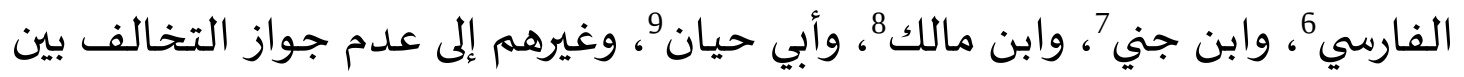
الصفة والموصوف في التعريف والتنكير .

2 مدحت محمد زيادة. النحو العربي بين الهنهج و التطبيق (الطبعة الأولى؛ القاهرة: مكتبة

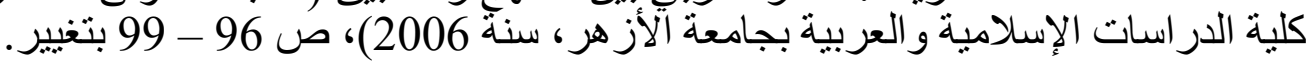

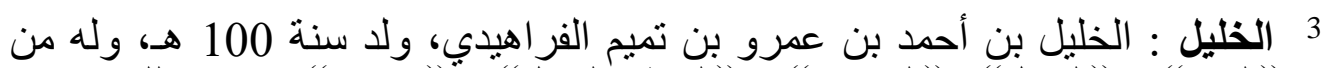

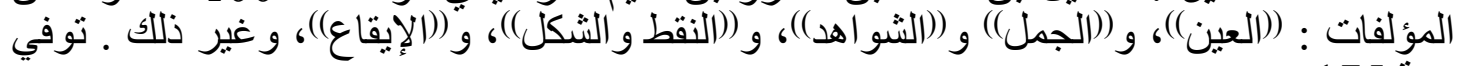
سنة 175 هـ ــ العير

ير اجع: الزبيدي. طبقات النحوبين واللغوبين (الطبعة الثانية؛ القاهرة: دار المعارف، سنة

$$
\text { 1973)، ص صنع. }
$$

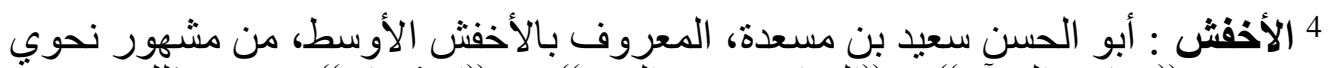

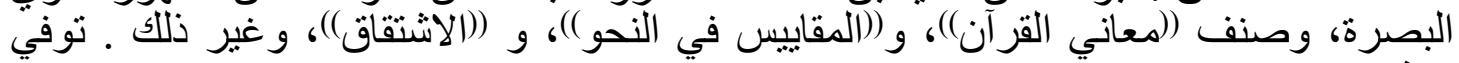
سنة 215 هـ

ير اجع : السيوطي. بغية الوعاة في طبقات اللغوبين والنحاة، الجزء الأول (الطبعة

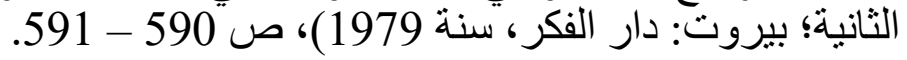

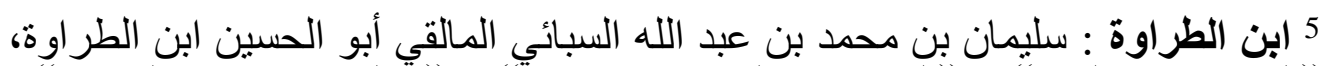

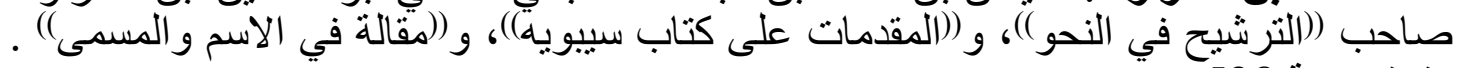
وتوفي سنة 528 هـ

ير اجع : السيوطي. بغبة الوعاة في طبقات اللغوبين والنحاة ، الجزء الأول، ص 602.

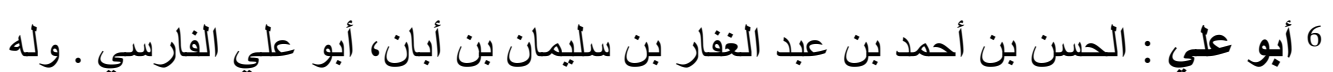

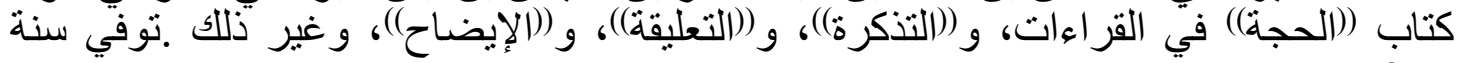

ير اجع: السيوطي. بغية الوعاة في طبقات اللغوبين و النحاة، الجزء الأول، ص 496 - 
1. قول النحويين بجواز وصف النكرة بالمعرفة:

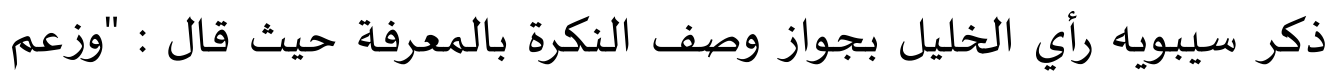

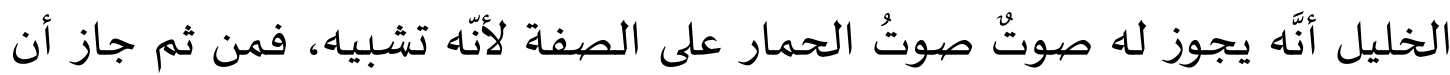

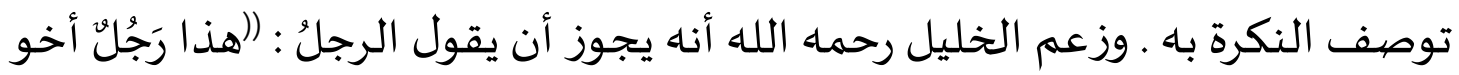

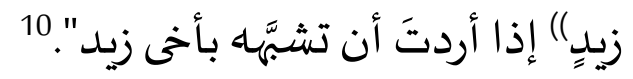

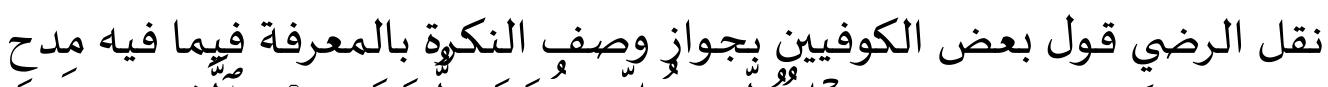

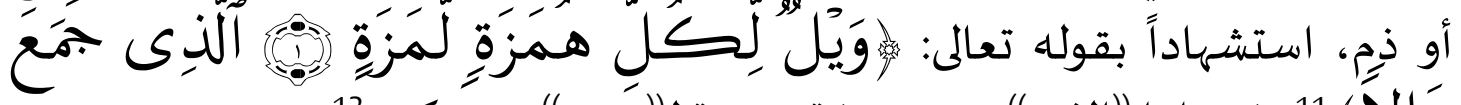

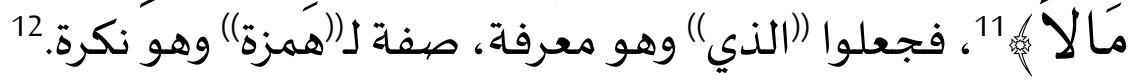

7 ابن جني : أبو الفتح عثمان بن جني الموصلي ، ولا قبل سنة 330 هـ ، و وله مصنفات

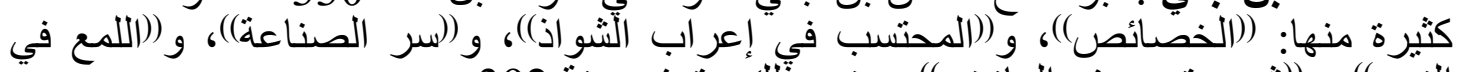

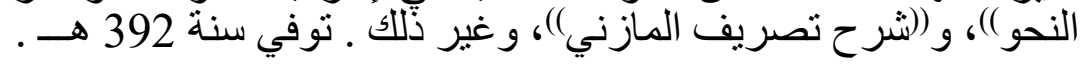

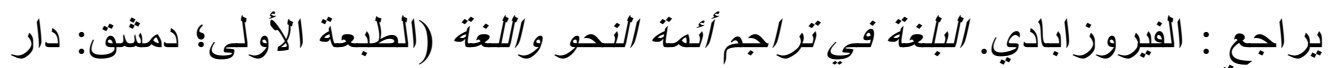
سعد الدين، سنة 2000)، ص ص 194 - 195.

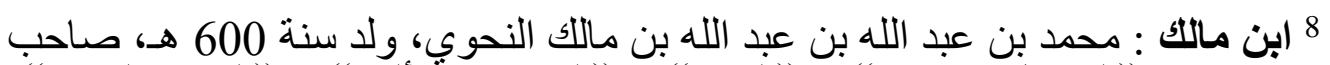
التصانيف، ومنها : ((التسهيل وشرحه))، و ((العددة))، و ((الخلاصة ألألفية))، و ((الكافية الثافية))، و ((نشواند التوضيح))، وغير ذللك ـ توفي سنة 672 هـ ـ.

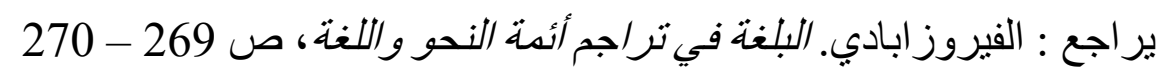

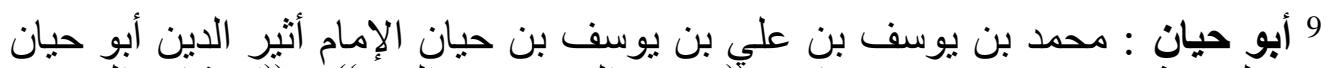

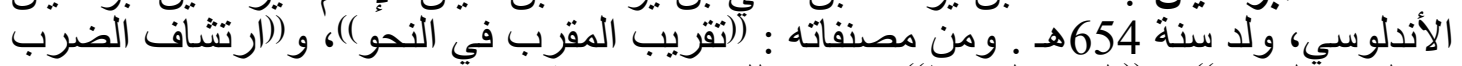

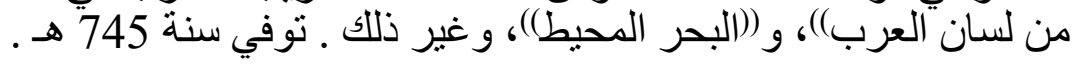

يراجع : خير الدين الزركلي. الأعلام، الجزء السابع (الطبعة الخامسة عشرة؛ بيروت: دار العلم للملايين، سنة 2002)، صئ الزئ 152. 10 سيبويه. الكتاب، الجزء الأول (الطبعة الثالثة؛ القاهرة: مكتبة الخانجي، سنة 1988)، ص ص 361.000

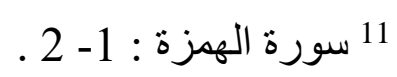
12 رضي الدين. شرح الرضي على الثئ الكافية، الجزء الثاني (الطبعة الثانية؛ بنغازي: جامعة خان يونس، سنة 1996)، ص صن الرين 307.

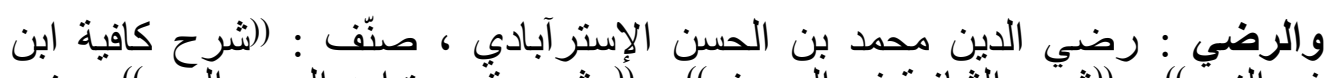

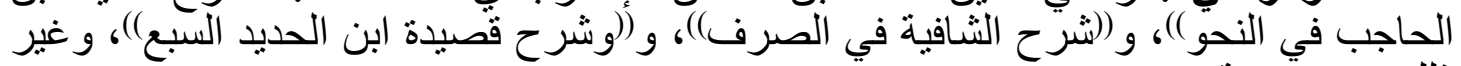
ذلك ـ توفي سنة 686 هـ . 


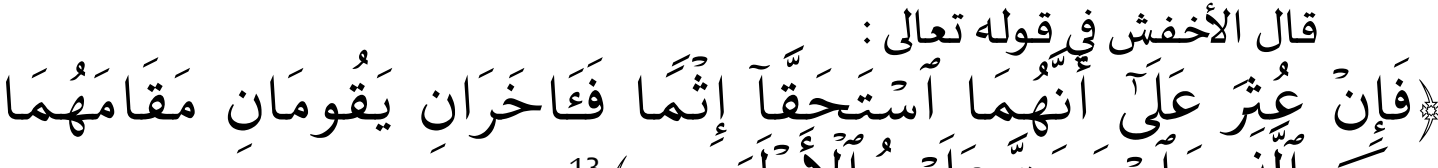

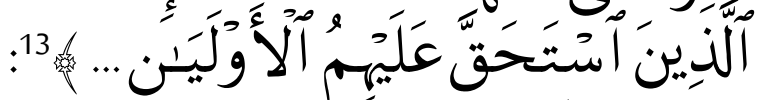

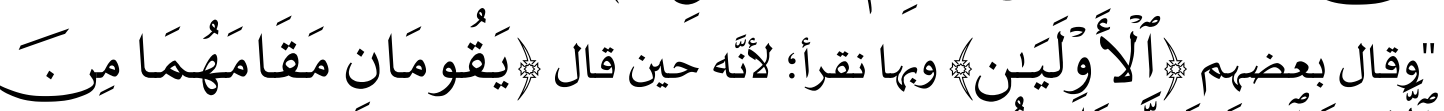

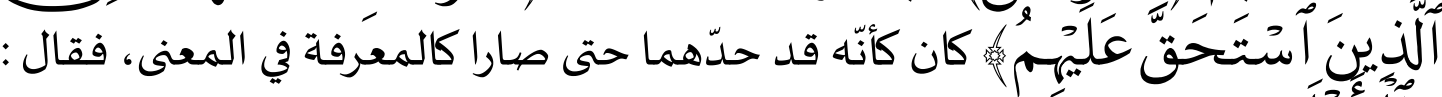

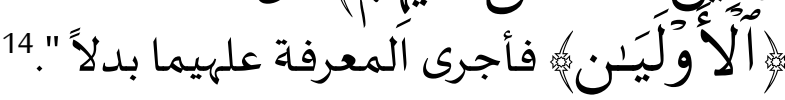

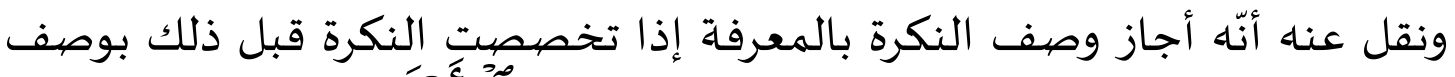

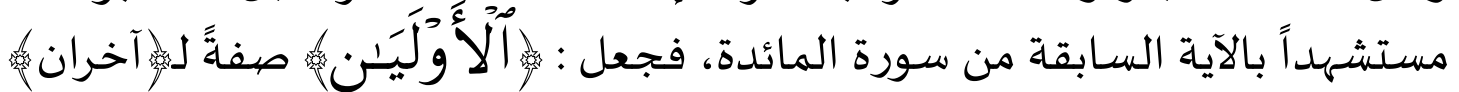
لماّ تخصصصت.

\section{2. قول النحوين بجواز وصف المعرفة بالنكرة}

أجاز بعض النحويين وصف المعرفة بالنكة ومنهم ابن الطراوة. قال ابن

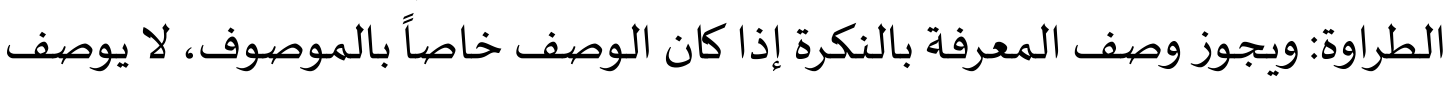
باه إلاّ ذلك الموصيوف كقول ولجور وهو الشـاعر :

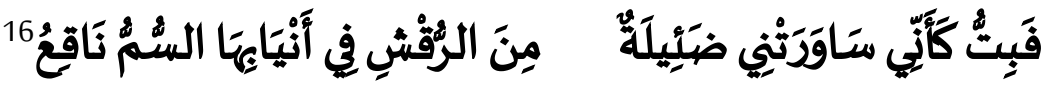

البيت من بحر الطويل وهو للنابغة الذبياني. واللغة فيه: قوله ((الساورتني)؛: واثبتني، و((ضئيلة)): أفعى دقيقة قد أتت عليها السنون، فقلّ لحمها واشتدّ سمها، و ((الرقش): جمع رقشاء، أفعى فيها نقاط بيضياء وسـوداء، و((ناقع)): قاتل. والشـاهد فياء

ير اجع : السيوطي. بغية الوعاة في طبقات اللغوبين والنحاة ، الجزء الأول، ص 567 -

13 سورة المائدة : 107 ـ 14

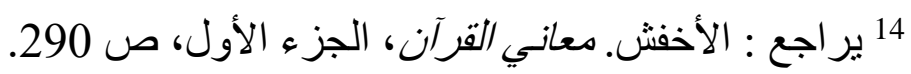

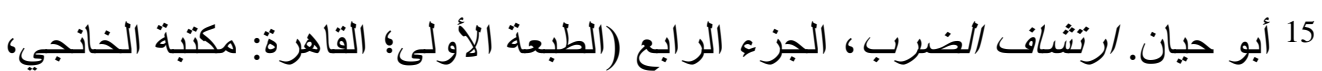

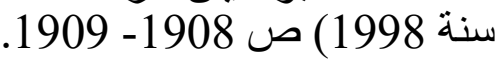

16 ير اجع البيت في : النابغة الذبياني. دبيوان النابغة، (مصر : دار المعارف)، ص 76،

وسييويه. الكتاب، الجزء الثاني، ص 89. 
: قوله ((السم ناقع)) حيث وقعت النكرة وهي ((ناقع)) صفة للمعرفة وهي ((السم)ر7)،

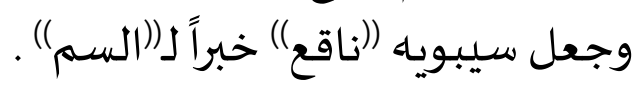

\section{3. قول النحويين بعدم جواز وصف النكرة بالمعرفة والعكس:}

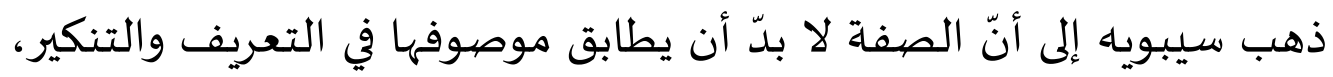

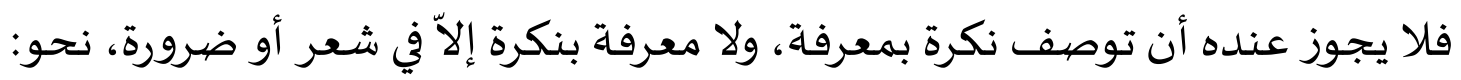

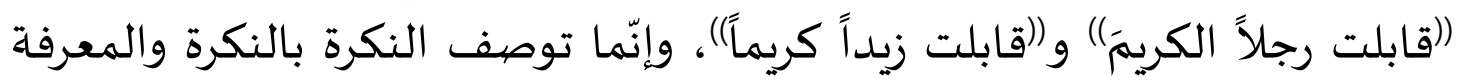

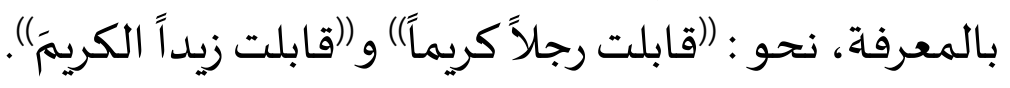

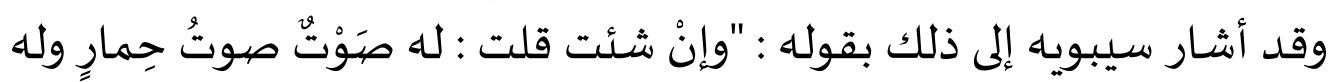

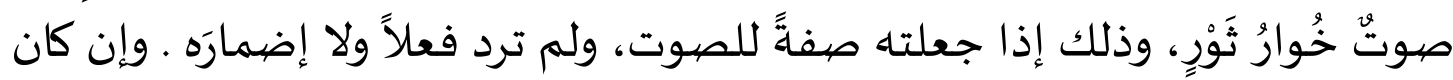

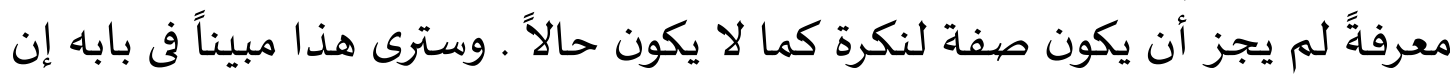

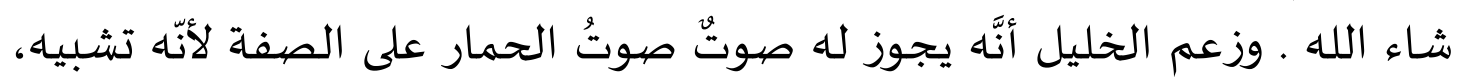

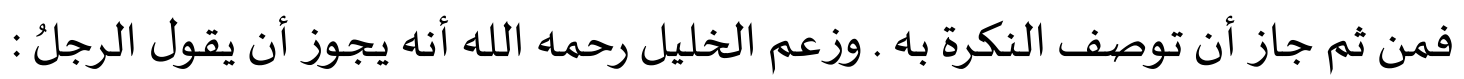

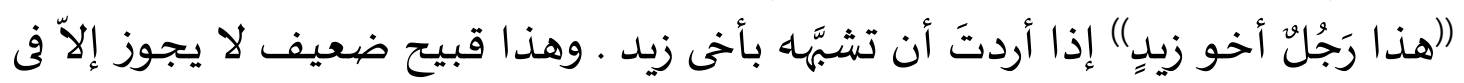

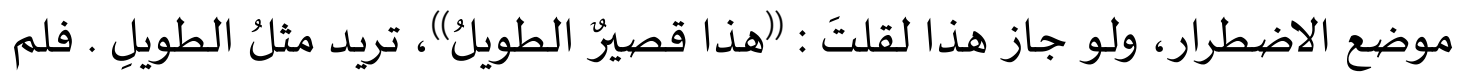

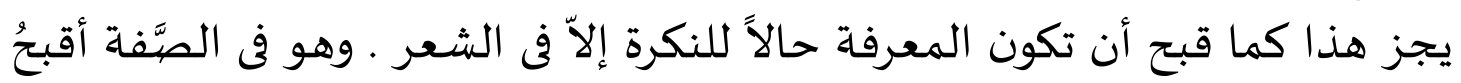

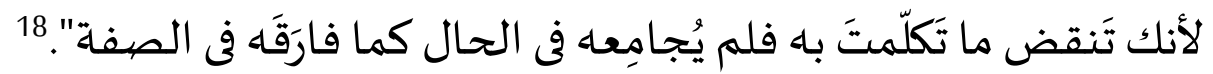

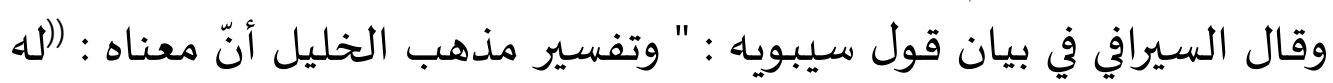

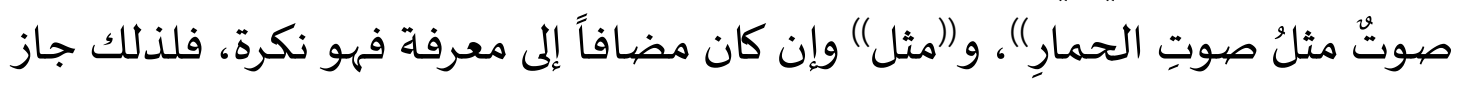

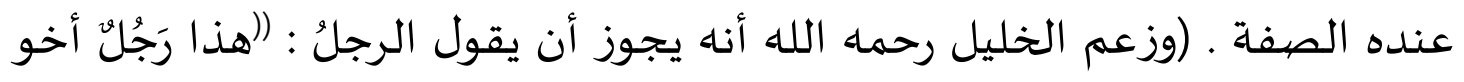

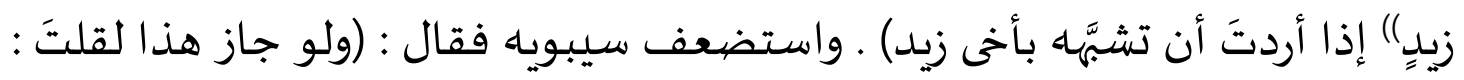

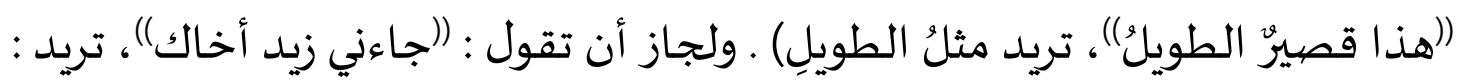

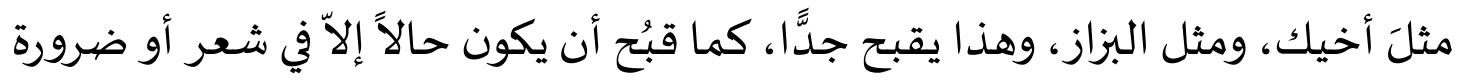

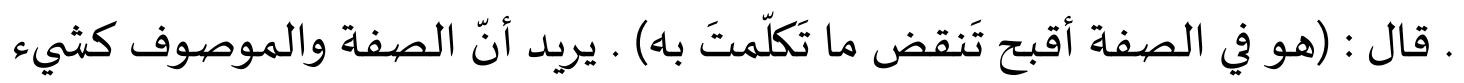

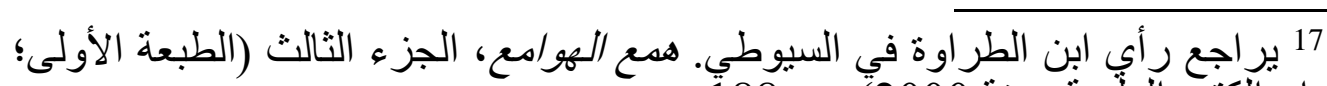

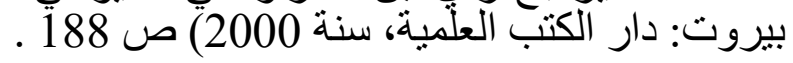

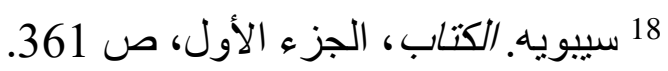


واحد، فلا يجوز أن يكون أحدُهما معرفةً والآخر نكرةً، والحال مع الذي منه الحال

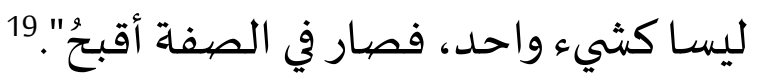

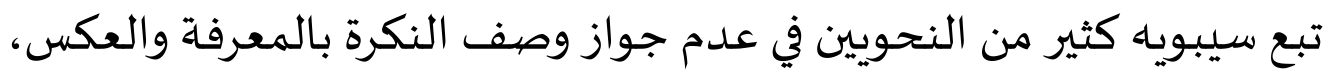

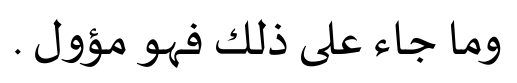

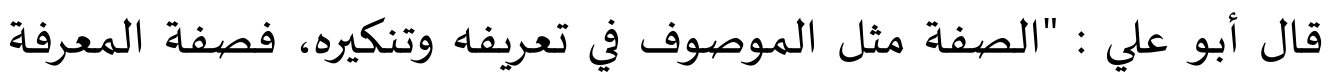

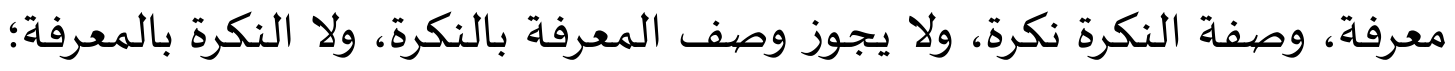

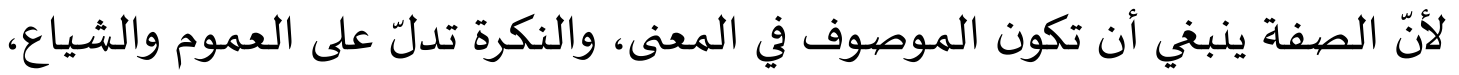

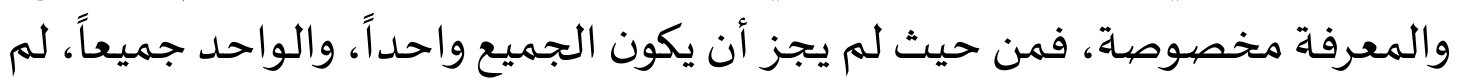

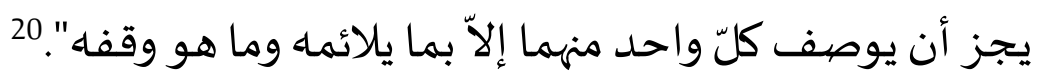

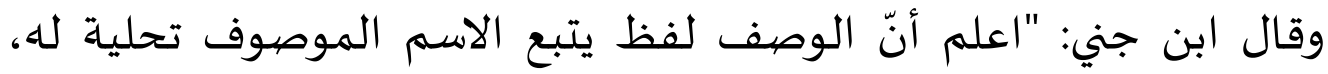

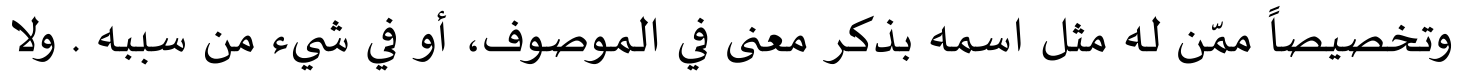

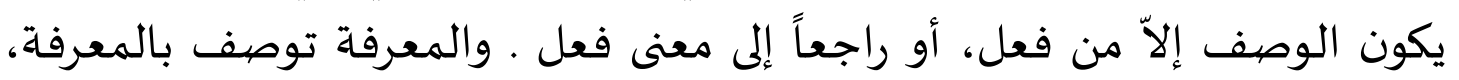

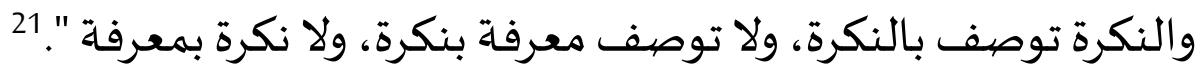

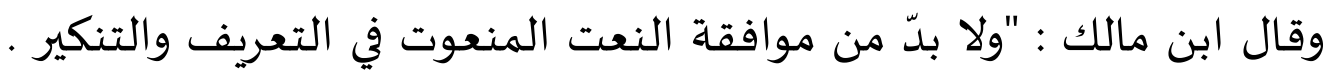

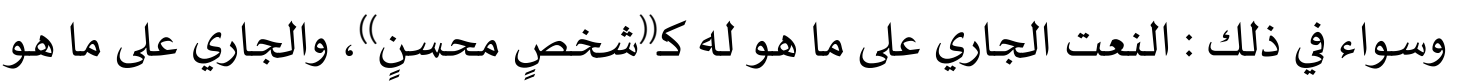

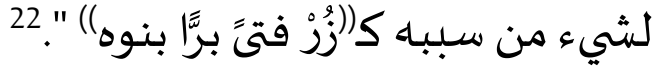

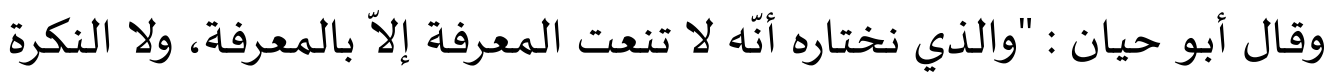
إلاّ بالنكرة إذا توافقا في الإعراب".

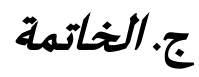

19 السيرافي. شرح كتاب سبيويه، الجزء الثاني (الطبعة الأولى؛ بيروت: دار الكتب

$$
\text { العلمية، سنة 2008)؛ ص } 248 \text { - } 249 .
$$

20 أبو علي الفارسي. الإيضاح (الطبعة الثانية؛ بيروت: عالم الكتب، سنة 1996)، ص

$$
21 \text { ابن جني. اللدع في العربية (عمان: دار مجدلاوي، سنة 1998)، ص } 65 \text {. }
$$

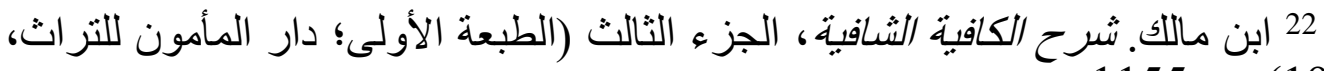

$$
23 \text { أبو حيان. ارتثاف الضرب، الجزء الرابع، ص } 1982
$$


وعلى الرغم من الخلافات الواقعة في وصف النكرة بالمعرفة وعكسه فإنني أرى الئ

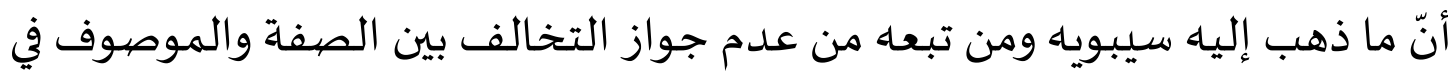
التعريف والتنكير هو الراجح؛ وذلك للأسباب التالية:

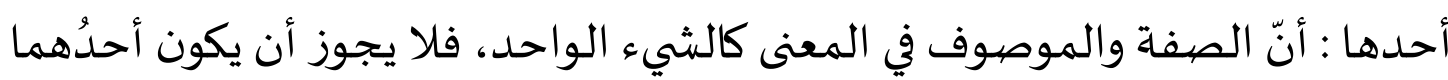

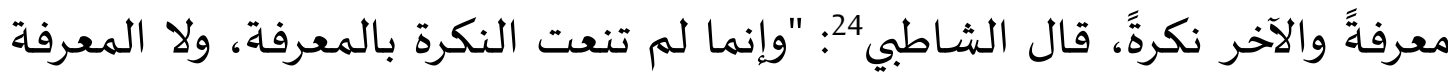

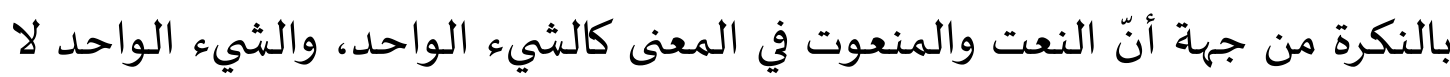
يكون معرفة ونكرة في حال".

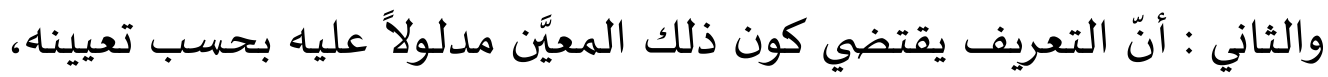

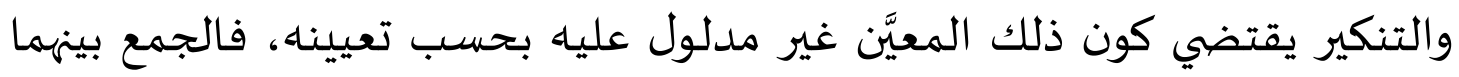

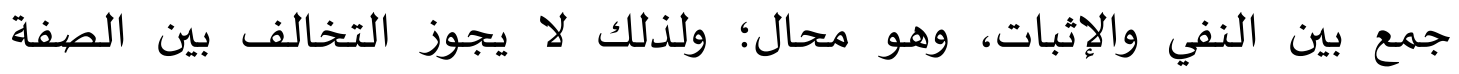
والموصوف في التعريف والتنكير.26

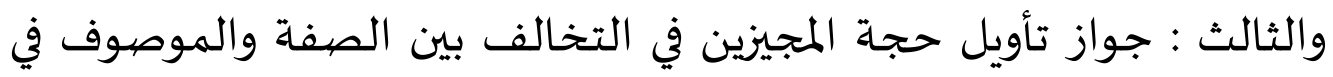

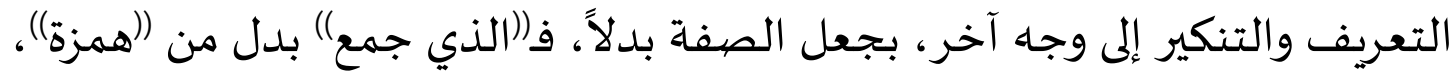

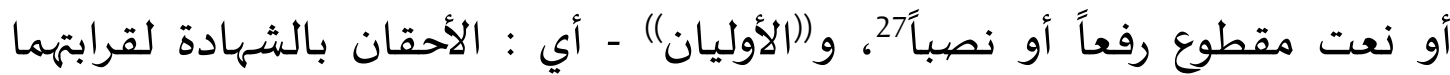

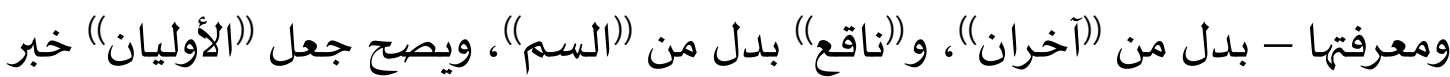

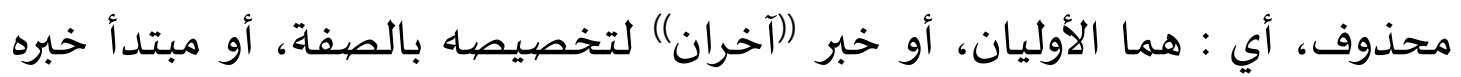

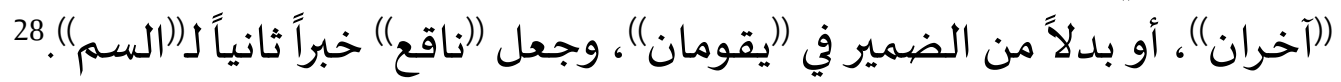

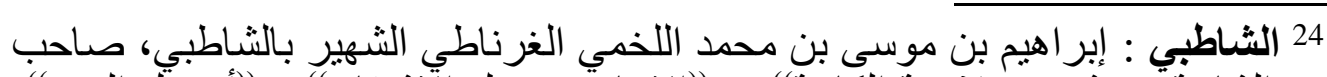

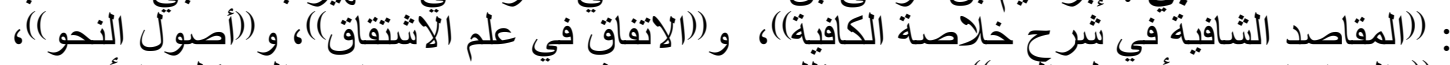

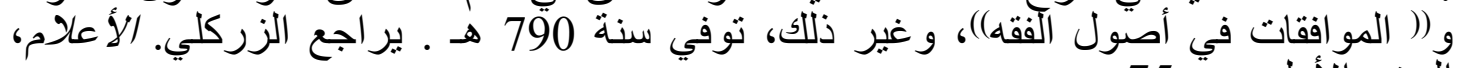

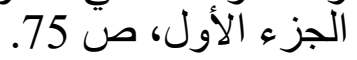

25 الثاطبي. الدقاصد الثافية، الجزء الرابع (الطبعة الأولى؛ مكة المكرمة: جامعة أم

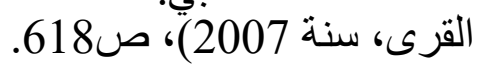
26 خالد الأزهري. شرح التصريح، الجزء الثاني (الطبعة الأولى؛ بيروت: دار الكتب

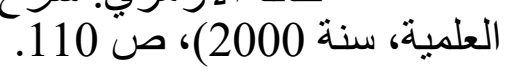

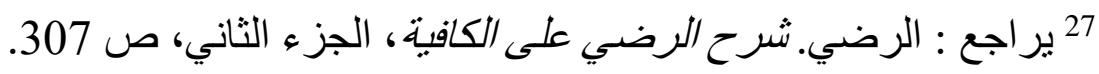

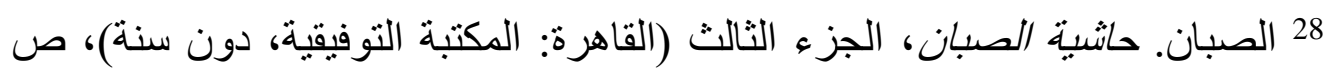




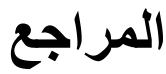

ابن الطراوة في السيوطي. هدع الهو/مع، الجزء الثالث (الطبعة الأولى؛

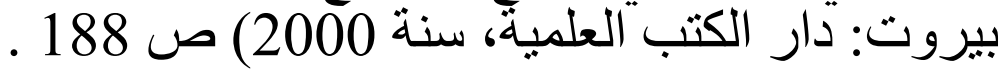

ابن جني. اللدع في العربية (عمان: دار مجدلاوي، سنة 1998)، ص صل 65 ـ

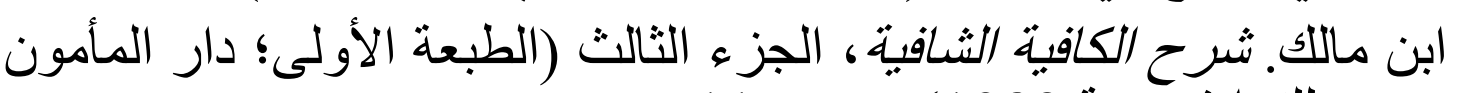

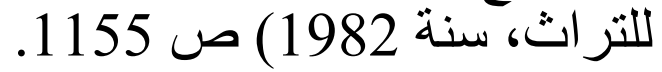

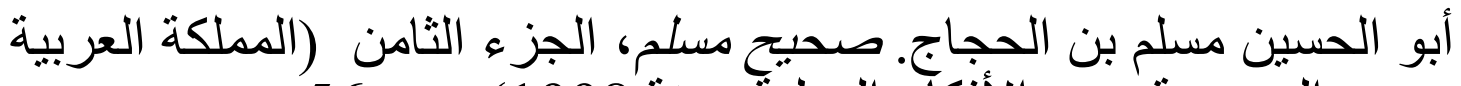

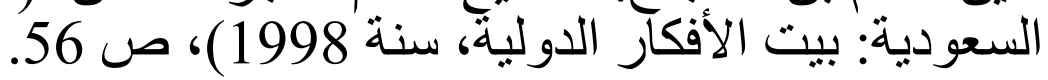

أبو حيان. ارتثاف الضرب، الجزء الرئ لابع (الطبعة الأولى؛ القاهرة: مكتبة الخانجي، سنة 1998) صن انس 1908- 1909.

أبو علي الفارسي. الإيضاح (الطبعة الثانية؛ بيروت: عالم الكتب، سنة 1996)، صل ص 215 -216. الأخفش. دعاني القرآن، الجزء الأول، ص ص 290. خالد الأزهري. شرح التصريح، الجزء التهاني الثراني (الطبعة الأولى؛ بيروت: دارئ دار

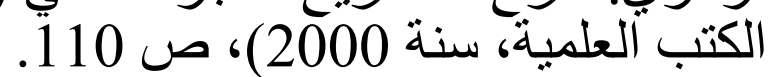

خير الدين الزركلي. الأعلام، الجزء السابع (الطبعة الخامسة عشرة؛

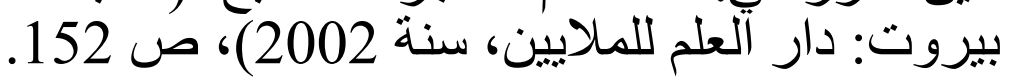

رضي الدين. شرح الرضسي على الكافية، الجزء الثة الثاني (الطبعة الثانية؛

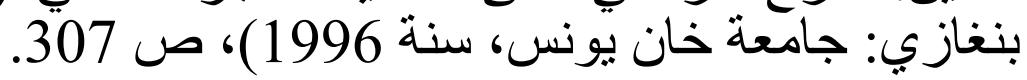

الزبيدي. طبقات النحوبين واللغوبين (الطبعة الثانية؛ القاهرة: دار المعارف، بونه، سنة 1973)، ص صن 47 - 51.

سيبويه. الكتاب، الجزء الأول (الطبعة الثالثة؛ القاهرة: مكتبة الخانجي، سنة

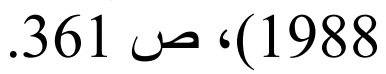


السير افي. شرح كتاب سيبويه، الجزء الثاني (الطبعة الأولى؛ بيروت: دار الكتب العلمية، سنة 2008)، ص صن 248 - 249.

السيوطي. بغية الوعاة في طبقات اللغوبين والنحاة، الجزء الجية الأول (الطبعة

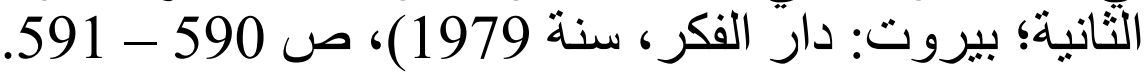

السيوطي. بغية الوعاة في طبقات اللغوبين والنحاة ، الجز ء الأول، ص 567 $.568-$

الثاطبي. المقاصد الثافية، الجزء الرابع (الطبعة الأولى؛ مكة المكرمة:

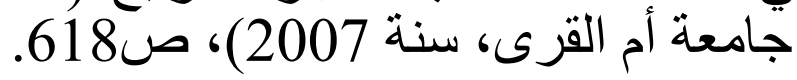

الصبان. حاثشية الصبان، الجزء الثالث (القاهرة: المكتبة التوفيقية، دون

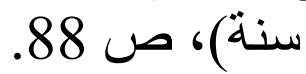

الفيروزابادي. البلغة في تراجم أئدة النحو واللغة (الطبعة الأولى؛ دمشق:

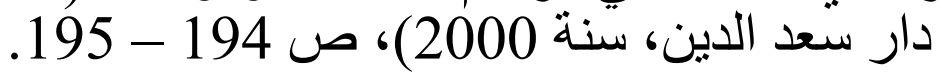

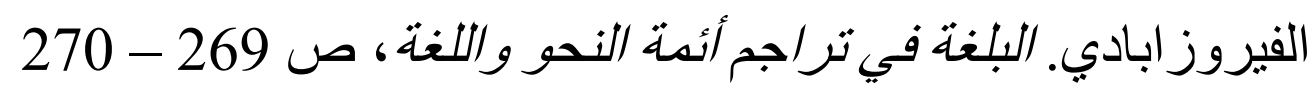

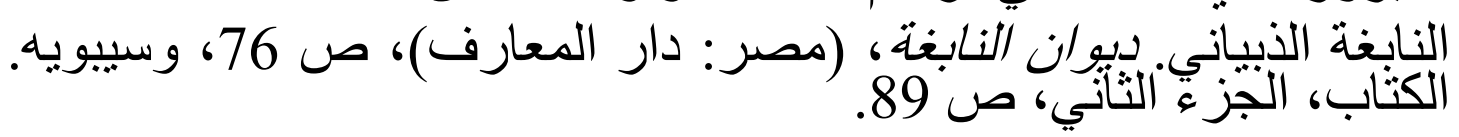


